Chapman University

Chapman University Digital Commons

Education Faculty Articles and Research

Attallah College of Educational Studies

$2-21-2018$

\title{
The Role of School Climate in Rates of Depression and Suicidal Ideation Among School-Attending Foster Youth in California Public Schools
}

Holly Shim-Pelayo

Kris Tunac De Pedro

Follow this and additional works at: https://digitalcommons.chapman.edu/education_articles

Part of the Curriculum and Social Inquiry Commons, Educational Assessment, Evaluation, and Research Commons, Educational Sociology Commons, Inequality and Stratification Commons, Other Education Commons, and the Race and Ethnicity Commons 


\section{The Role of School Climate in Rates of Depression and Suicidal Ideation Among School-Attending Foster Youth in California Public Schools}

\section{Comments}

NOTICE: this is the author's version of a work that was accepted for publication in Children and Youth Services Review. Changes resulting from the publishing process, such as peer review, editing, corrections, structural formatting, and other quality control mechanisms may not be reflected in this document. Changes may have been made to this work since it was submitted for publication. A definitive version will be subsequently published in Children and Youth Services Review, in 2018. DOI: 10.1016/j.childyouth.2018.02.033

The Creative Commons license below applies only to this version of the article.

\section{Creative Commons License}

\section{(c) 1 (1) 90}

This work is licensed under a Creative Commons Attribution-Noncommercial-No Derivative Works 4.0 License.

\section{Copyright}

Elsevier 


\section{Accepted Manuscript}

The role of school climate in rates of depression and suicidal ideation among school-attending foster youth in California public schools

瑥

CHILDREN

and

YOUTH

SERVICES

REVIEW

Holly Shim-Pelayo, Kris Tunac De Pedro

PII: $\quad$ S0190-7409(17)30918-0

DOI:

doi:10.1016/j.childyouth.2018.02.033

Reference:

CYSR 3702

To appear in:

Children and Youth Services Review

Received date:

24 October 2017

Revised date:

17 February 2018

Accepted date:

17 February 2018

Please cite this article as: Holly Shim-Pelayo, Kris Tunac De Pedro, The role of school climate in rates of depression and suicidal ideation among school-attending foster youth in California public schools. The address for the corresponding author was captured as affiliation for all authors. Please check if appropriate. Cysr(2017), doi:10.1016/ j.childyouth.2018.02.033

This is a PDF file of an unedited manuscript that has been accepted for publication. As a service to our customers we are providing this early version of the manuscript. The manuscript will undergo copyediting, typesetting, and review of the resulting proof before it is published in its final form. Please note that during the production process errors may be discovered which could affect the content, and all legal disclaimers that apply to the journal pertain. 
The Role of School Climate in Rates of Depression and Suicidal Ideation among SchoolAttending Foster Youth in California Public Schools

Holly Shim-Pelayo ${ }^{a}$ and Kris Tunac De Pedro ${ }^{b}$

${ }^{a}$ University of Southern California, 3470 Trousdale Pkwy, Los Angeles, CA 90089 (U.S)

${ }^{\mathrm{b}}$ Chapman University, One University Dr, Orange, CA 92866 (U.S)

Corresponding author: hollyshi@usc.edu and holly.shim@gmail.com 


\begin{abstract}
Drawing from the 2013-2014 and 2014-2015 administrations of the California Healthy Kids Survey, this study explored the relationships between school climate and depression tendency and suicidal ideation among foster youth in California public schools. This research also evaluated the data for the secondary purpose of examining the possible differences in the levels of depression tendency and suicidal ideation among foster youth by race and gender. Findings indicated a positive school climate is associated with lower rates of depression tendency and suicidal ideation among foster youth. In addition, female foster youth reported higher rates of depression tendency and suicidal ideation when compared to their male counterparts. We also discovered foster youth of color were significantly less likely to report depression tendency and suicidal ideation than their White peers. Results of this study stand to inform current and future school-based programs and supports for foster youth.
\end{abstract}

Keywords: foster youth, depression, suicidal ideation, school climate

\title{
1. Introduction
}

Over half a million children are currently placed in foster care in the U.S. (Pilowsky \& $\mathrm{Wu}, 2006)$. The foster care system is considered a hub for behavioral care systems, given the disproportionate number of children with clinically significant emotional and behavioral issues (Pilowsky \& Wu, 2006). Research has found that foster youth cope with daily life challenges, including unstable household environments, neglect, lack of social support, and school mobility (Pilowsky \& Wu, 2006; Stoner, Leon, \& Fuller, 2015; Zetlin, MacLeod, \& Kimm, 2010). Not surprisingly, studies have revealed youth in the foster care system were more likely to have emotional and behavioral disorders (Pilowsky \& Wu, 2006; Stoner, Leon, \& Fuller, 2015; Zetlin, 
MacLeod, \& Kimm, 2010). Zetlin et al. (2010) concluded foster youth were more likely to have academic and mental health problems. Moreover, children and adolescents in the foster care system were more likely to engage in substance use and abuse when compared to the general youth population (Pilowsky \& Wu, 2006; Stoner et al., 2015). Long-term psychological issues such as depression, anxiety, or posttraumatic stress syndrome disorder (PTSD) stemming from trauma, abuse, or neglect were common among foster youth (Harris, Jackson, O’Brien, \& Pecora, 2010; Pilowsky \& Wu, 2006).

Within the larger foster youth population, smaller subgroups contend with even greater risk of mental health problems (Pilowsky \& Wu, 2006; Stoner et al., 2015). Racial minority youth in foster care system not only face challenges that foster youth typically experience, but they also encounter daily episodes of racial discrimination in schools, communities, and other social contexts (Brand, Felner, Shim, Seitsinger, \& Dumas, 2003; Elliot, Cornell, Gregory, \& Fan, 2010; Huang, Eklund, \& Cornell, 2016; O’Malley, Voight, Renshaw, \& Eklund, 2015; Thapa, Cohen, Guffey, \& Higgins-D’Allesandro, 2013). In addition, when compared to male youth, research has found that female youth have higher levels of depression tendency and suicidal ideation (Cyranowski et al., 2000). To date, studies have yet to systematically examine racial differences in mental health problems among youth in foster care. Such knowledge would be useful for practitioners working with foster youth.

Research has established that a positive school climate plays a protective role in the social and emotional outcomes of youth facing adversity (Brand, Felner, Shim, Seitsinger, \& Dumas, 2003; Elliot, Cornell, Gregory, \& Fan, 2010; Huang, Eklund, \& Cornell, 2016; O’Malley, Voight, Renshaw, \& Eklund, 2015; Thapa, Cohen, Guffey, \& Higgins-D’Allesandro, 
2013). However, only a few studies have explored the relationship between school climate and academic outcomes among youth in foster care (Huang et al., 2016; O’Malley et al., 2015). This study addresses these research gaps by exploring racial and gender differences in mental health outcomes and associations between school climate, depression, and suicidal ideation in a diverse statewide sample of youth.

\subsection{The life challenges of foster youth}

Foster youth experience tremendous stress as a result of barriers and challenges in the foster care system and the schools they attend (Stoner et al., 2015; Sullivan, Jones, \& Mathieson, 2010). For instance, research has brought to light multiple entities — school districts, child welfare services, legal services — coordinate the educational placements of foster youth; delays in schools receiving timely information about students in the foster care system occur often (Sullivan et al., 2010). School professionals wait an average of two months to retrieve a student's record from the foster care system (Sullivan et al., 2010). Not only is the information on foster youth often delayed, but research has also reported that some records are inaccurate. Foster youth may also experience multiple school placement changes, which adversely impact healthy student development and proper cultivation of relationships with teachers and peers (Sullivan et al., 2010)). Furthermore, foster youth experience multiple changes in the family structure throughout the foster care process (e.g., foster family, biological and/or legal parent, or guardian), which place them at a higher risk of lower academic achievement, and increased instances of depression tendency and suicidal ideation (Stoner et al., 2015; Sullivan et al., 2010). Overall, accumulated stress from challenges in school, the foster care system, and other contexts increases the risk of foster youth to developing damaging mental health (O'Malley et al., 2015; Stoner et al., 2015). 


\subsection{Mental health problems among foster youth}

The life challenges of foster youth adversely impact their social and emotional well-being and mental health (O'Malley et al., 2015). Stoner et al. (2015) discovered that foster youth were nearly eight times more likely to have a diagnosis of mental illness when compared to non-foster youth. Their study further indicated that adolescents in foster care demonstrate significantly higher rates of past-year psychiatric symptoms than those never placed in foster care. In a national study of mental health and substance use disorders, Pilowsky and Wu (2006) concluded adolescents in foster care were about four times more likely to have attempted suicide in the past 12 months. Depression tendency and suicidal ideation, in the long-term, can have an adverse impact on an array of behavioral and academic outcomes among foster youth (Keller, Salazar, \& Courtney, 2010). As an example, findings from Keller et al. (2010) pointed out that depression in adolescence was associated with elevated rates of substance use, academic underachievement, employment difficulties, risky sexual behavior, and teenage pregnancy among foster youth. Further, a national study of adolescents found that within the foster youth population, depressive symptoms were associated with a higher likelihood of substance use (Pilowsky \& Wu, 2006). The current study contributes to the growing literature base on mental health outcomes of foster youth by placing a focus on depression tendency and suicidal ideation, two indicators of mental health problems among adolescents.

\subsection{Differences in mental health outcomes among foster youth by race and gender}

Research on racial differences in mental health outcomes among foster youth continues to emerge. However, of the available studies, results have been mixed (Daining \& DePanfilis, 2007; Dworsky et al., 2010; Harris et al., 2010). Research has found that White foster youth were nearly three times more likely than Black foster youth to have a lifetime diagnosis of depression 
(Sullivan, Jones, \& Mathiesen, 2010). Similarly, Harris et al. (2010) found that Black foster youth had significantly lower odds of lifetime mood and anxiety disorders than White foster youth. Their study went on to suggest that Black foster youth had greater persistence of any chronic disorder and chronic anxiety when compared to White foster youth. In contrast, Harris et al. (2010), have reported no differences, in terms of race, in past-year depression tendency among foster youth (Dworsky et al., 2010). As discussed, available research has generated mixed results around racial differences and past-year depression tendency among foster youth. On that note, this study aims to shed light on racial differences in depression tendency and suicidal ideation among foster youth.

Within the foster youth population, girls may also be especially at risk of depression tendency and suicidal ideation. To the author's knowledge, there are no studies, at present, that have investigated gender differences in mental health outcomes among foster youth. There, however, exists research that has addressed gender differences in the general youth population (Cyranowski, Frank, \& Young, \& Shear, 2000; Nolen-Hoeksema \& Girgus, 1994). NolenHoeksema and Girgus (1994) theorized that the causes of depression among girls become prevalent in early adolescence. Before early adolescence, girls are more likely than boys to carry risk factors for depression. Along the same line, Cyranowski et al. (2000) discovered females, by the age of 15 , are nearly twice as likely as males to have experienced depression. Their data also suggested the risk factors for depression in female adolescents, as compared to their male peers, can persist upwards of 35 to 40 years. Results further acknowledge that females are more likely than males to become depressed when faced with negative life events (Cyranowski et al., 2000). The current study addresses a gap in the research by examining gender differences in depression tendency and suicidal ideation among foster youth. 


\subsection{The potential role of a supportive school climate in the lives of youth in foster care}

As a psychologically strained youth population, youth in foster care may benefit from a supportive and caring school environment. Decades of research have highlighted the effects of a caring school climate on the well-being of youth populations, especially those facing adversity and stress in their home, school, and other social contexts (De Pedro et al., 2014; Thapa et al., 2013; Vacca, 2008). School climate research and the theories they generate span over almost a century. Their philosophical roots appeared in the writings of Dewey and Piaget, early advocates of the critical role supportive school environments have on youth. Translating these findings into school reform, scholars and practitioners have developed and led school and community-wide programs that promote healthy social and psychological development for youth in high poverty communities. From the late 19th century into the 20th century, reform efforts such as Hull House in Chicago, Comer's (1984) School Development Program in the New Haven School District in the 1970s and 1980s, and Dryfoos's (1995) framework of a full-service urban school have provided school practitioners with strategies to support youth facing adversity. More recently, research on trauma-informed approaches in schools has explored the significance of a positive school climate for students exposed to high levels of family and environmental stress (Anderson, Blitz, \& Saastmoinen, 2015, Brand, Felner, Shim, Seitsinger, \& Dumas, 2003; Elliot et al., 2010; O’Malley et al., 2015; Thapa et al., 2013).

More and more, researchers have argued for studies to utilize measures that assess the multiple dimensions of school climate (Anderson, Blitz, \& Saastmoinen, 2015, Brand, Felner, Shim, Seitsinger, \& Dumas, 2003; Elliot et al., 2010; O’Malley et al., 2015; Thapa et al., 2013). The current study draws from multiple components of school climate, which have been assessed in previous studies, such as caring relationships, high expectations from school adults, perceived 
safety, and meaningful participation. These dimensions of school climate promote well-being, academic success, and pro-social behavior among youth, in general (Elliot et al., 2010; Marachi, Astor, \& Benbenishty, 2006; Thapa et al., 2013; Wilson, 2004). A positive and caring social and emotional school climate has also been associated with a wide array of outcomes - some positive and some negative - among youth (Cornell \& Huang, 2016; Thapa et al., 2013). Outcome types include academic (i.e., attendance, motivation, and test scores), risky behaviors (i.e., bullying, aggression, risky sexual behavior, alcohol, and drug use), and psychological (i.e., depression, anxiety, and psychiatric disorders) (Cornell \& Huang, 2016; O’Malley et al., 2015; Huang et al., 2017). School climate has a protective effect on youth facing adversity in various geographical contexts (Astor, Benbenishty, \& Estrada, 2009; Cohen, McCabe, Michelli, \& Pickeral, 2009; De Pedro, Astor, Gilreath, Benbenishty, \& Berkowitz, 2015; Thapa et al., 2013). As evidenced above, even with all the available research to date, there still remains a lack of studies that have examined school climate as it pertains to foster youth outcomes; moreover, of the extant research, the focus has been on academic outcomes (Huang et al., 2017). As one example, Huang et al. (2017) found that academic expectations and student support were highly associated with grade point average among students not living with any parent. This current study builds on past research by exploring the relationship between school climate and depression tendency and suicidal ideation among foster youth in a large statewide sample of youth attending California schools.

\subsection{Study objectives}

Existing research has yet to determine the role of school climate on the mental health outcomes of foster youth. Furthermore, there has only been a limited number of studies, which have examined differences in mental health by race and gender within the foster youth 
population. Given these gaps in the research, our study explores the relationships among school climate, depression tendency, and suicidal ideation among foster youth. More specifically, we will draw from a sample of racially diverse foster youth attending California public schools to examine differences in depression tendency and suicidal ideation by race and gender. Taking into consideration past research, we posit that rates of depression tendency and suicidal ideation will be higher among female foster youth when compared to male foster youth. We also anticipate that higher levels of school climate are associated with lower odds of depression tendency and suicidal ideation among foster youth, controlling for demographics (i.e., race, gender, and grade level). Given limited research on racial differences among foster youth, it is not feasible to provide a hypothesis.

The following research questions guide the current study:

1. Do race and gender influence rates of depression tendency and suicidal ideation among foster youth?

2. Controlling for student demographics (i.e., race, gender, and grade level), what is the relationship between school climate and depression tendency and suicidal ideation among foster youth in California schools?

\section{Methods}

This research did not receive any specific grant from funding agencies in the public, commercial, or not-for-profit sectors. This study is a secondary analysis of the 2013-2014 and 2014-2015 administrations of the California Healthy Kids Survey (CHKS). The California Department of Education (CDE) and WestEd (a nonprofit and nonpartisan research, development, and service agency) led the 2013-2014 and 2014-2015 administrations of the 
CHKS. The CHKS is the largest statewide survey of elementary, middle, and high school students' perceptions of school support, bullying, substance use, and resiliency in the U.S. (Austin, Bates, \& Duerr, 2014). The survey is comprised of a required core module that assesses student demographic characteristics (e.g., foster youth, grade, biological sex, and race and ethnicity), mental health (e.g., suicidal ideation), peer victimization at school, and health risk behaviors (Austin et al., 2014). The CDE requires that school districts administer the survey to a district-wide representative sample of students in the 5th, 7th, 9th, and 11 th grades. The present study included 9th and 11th graders, and excluded 5th and $7^{\text {th }}$ graders as the CHKS did not ask 5th and 7th graders any survey items on whether or not they were in foster care.

The CHKS sampling procedure included: 1) All (100\%) district schools participate; or all (100\%) selected schools from an approved sampling plan take part in the survey; 2) The district identified a class session where all participants were in attendance; 3) All (100\%) selected classrooms participated; and 4) The number of completed, usable answer forms obtained per grade was $60 \%$ or more of the sample; or 5) If a district obtained active parental consent, $70 \%$ or more parents within each grade's selected sample returned signed permission forms, consenting or non-consenting to their child's participation in the survey.

\subsection{Participants and consent procedures}

Prior to the administration of the CHKS, Wested and CDE obtained a completed consent from a parent and/or guardian (i.e., foster parent) from each student participant from each school district. School staff familiar with the CHKS survey administration or WestEd proctors (if a school site decided to hire professionally trained survey proctors) administered the CHKS to student participants. WestEd and CDE provided all survey administrators with proctoring instructions before the survey administration. As scripted, proctors read an introduction to the 
survey to all student participants, encouraged students to answer all questions honestly, and stated that all responses would be anonymous. Proctors also informed student participants that they were permitted to withdraw from the survey at any time. The CHKS took approximately 50 minutes to complete.

This study utilized data from the 2013-2014 and 2014-2015 administrations of the CHKS. Specifically, this study drew from the overall sample of students who participated in the survey $(\mathrm{N}=323,715)$ and a subsample of students who identified as living in a foster home, group care, or waiting for placement $(n=1354)$. In addition to the CHKS consent-obtaining process, administrators also followed district-level consent procedures. Given that the CHKS is a publicly available, de-identified database, the current study did not require oversight from the university institutional review board. A weighing procedure was used to adjust the total number of grade level respondents to represent the total district enrollment for the particular grade levels of interest. Additionally, district level clustering was also taken into account.

\subsection{Measures}

This study included two dependent variables to assess depression tendency and suicidal ideation, which previous studies have used (Cederbaum et al., 2014; Moore, Benbenishty, Astor, \& Rice, 2017). The CHKS asked students whether or not they felt so sad or hopeless almost every day for two weeks or more that they stopped doing some usual activities during the past 12 months. The survey also asked students to report whether or not they seriously considered attempting suicide during the past 12 months.

The current study also examined student self-reported demographic variables_ - grade level, race and ethnicity, and gender. Ninth grade was used as the reference category and 11th grade was used as the dummy variable. As one category, race and ethnicity was represented by 
White as the reference category, and the dummy variables were Black, American Indian/Alaskan Native, Asian/Pacific Islander (PI), Latino, and multiracial.

Items related to the four dimensions of school climate - school connectedness, caring relationships, high expectations, and meaningful participation-were also included. These scales have been validated and used as measures of school climate in previous research (De Pedro, Esqueda, \& Gilreath, 2017; De Pedro et al., 2015; De Pedro, Gilreath, \& Berkowitz, 2016). The school connectedness scale was a summed scale that included three items $(\alpha=.80)$. Students reported whether they felt close to people at their school; are happy to be at their school; or feel like they are part of their school. The possible responses for these items were assessed in a fourpoint Likert scale, with $1=$ Not At All True; $2=$ A Little True; $3=$ Pretty Much True; and $4=$ Very Much True. Values for this scale ranged from a minimum of 3 to a maximum of 12 . The caring relationship scale was also a summed scale, consisting of three self-reported items $(\alpha=$ .78). Students reported whether there is a teacher or some other adult at school who tells them when they do good; who notices when they're not there; or who listens to them when they have something to say. The responses to these items were on a four-point Likert scale, ranging from 1 $=$ Not At All True; 2 = A Little True; 3 = Pretty Much True; and $4=$ Very Much True. The high expectations scale included three self-reported items $(\alpha=.82)$. Students reported whether at school there is a teacher or some other adult who tells them they do a good job; who always wants them to do their best; or who believes they will be a success. The responses to these items were on a four-point Likert scale, with 1 = Not At All True; 2 = A Little True; $3=$ Pretty Much True; and $4=$ Very Much True. The meaningful participation scale consisted of three items $(\alpha=$ .74). They include: I do interesting activities at school; I help decide things like class activities; or I do things that make a difference. The possible responses to these items were on a four-point 
Likert scale and ranged from $1=$ Not At All True; $2=$ A Little True; $3=$ Pretty Much True; and $4=$ Very Much True.

\subsection{Analytical plan}

We used IBM SPSS Version 24 to perform all analyses. Descriptive and multivariate analyses were conducted to address the goals of this study. We first conducted bivariate analyses (chi-square tests of association) to explore differences in rates of depression tendency and suicidal ideation by race and gender. Multivariable logistic regression analyses were then conducted to assess the relationship between multiple components of school climate and depression tendency and suicidal ideation, controlling for grade level, biological sex, and race and ethnicity. A hierarchical linear model was considered for this study. Several school climate studies have accounted for between-school variation. However, we found that intra-class correlation coefficients were well below .01, indicating that there was more within-school variation than between-school variation in school adult support and school connection. As such, perceived school adult support and perceived school connection were analyzed as individuallevel variables.

\section{Results}

\subsection{Sample characteristics}

The subsample of foster youth was racially diverse (see Table 1). Over half of the sample (54.5\%) identified as Latino. About $13.6 \%$ of the participants reported multiracial identity, while 9.2\% identified as Black and 3.1\% identified as American Indian/Alaskan Native. Moreover, the foster youth sample was about $58.3 \%$ female and $41.7 \%$ male. About $51.5 \%$ of foster youth were in the 9 th grade, while $48.5 \%$ reported being in the 11 th grade. Roughly $29.7 \%$ of the 
sample reported suicidal ideation in the past 12 months, while $42.5 \%$ reported feeling sad in the past 12 months.

\subsection{Differences in Suicidal Ideation and Chronic Sadness by Race and Gender}

Results from chi-square tests of association indicated significant racial differences in depression tendency $\left(X^{2}=14.26, \mathrm{df}=5, \mathrm{p}<.01\right)$ and suicidal ideation $\left(X^{2}=20.41\right.$, df $=5, \mathrm{p}<$ $.01)$ and in the foster youth subsample. Over half of White foster youth (52.5\%) reported pastyear depression tendency, compared to $30.2 \%$ of American Indian youth, $40.7 \%$ of Asian/PI youth, $37.5 \%$ of Black youth, $43.7 \%$ of multiracial youth, and $43.4 \%$ of Latino youth. About $40.7 \%$ of White foster youth reported past-year suicidal ideation, compared to $24.5 \%$ of American Indian youth, 22.6\% of Asian/PI youth, 25.3\% of Black youth, 33.0\% of multiracial youth, and $28.1 \%$ of Latino youth. The results showed significant differences in suicidal ideation $\left(X^{2}=46.89, \mathrm{df}=1, \mathrm{p}<.01\right)$ and depression tendency $\left(X^{2}=54.60, \mathrm{df}=1, \mathrm{p}<.01\right)$ by gender. About $50.5 \%$ of female foster youth reported depression tendency, compared to $32.7 \%$ of male foster youth. More than one-third (36.3\%) of female foster youth reported suicidal thoughts, compared to $21.0 \%$ of male foster youth.

\subsection{Multivariable results}

Results from the multivariable logistic regression analyses indicated some racial differences in suicidal ideation and feeling sad among foster youth (see Table 2). When compared to White peers, Latino foster youth were $46 \%$ less likely to report suicidal ideation $(\mathrm{AOR}=0.54 ; \mathrm{CI}=0.37-0.79)$ and $35 \%$ less likely than White peers to report depression tendency $(\mathrm{AOR}=0.65 ; \mathrm{CI}=0.45-0.94)$. Also, Asian/PI foster youth were $62 \%$ less likely than White peers to report suicidal ideation $(\mathrm{AOR}=0.49 ; \mathrm{CI}=0.28-0.83)$. Black foster youth were also significantly less likely to report depression tendency than White peers $(\mathrm{AOR}=0.49 ; \mathrm{CI}=$ 
$0.28-0.83)$ and suicidal ideation $(\mathrm{AOR}=0.36 ; \mathrm{CI}=0.20-0.65)$. The results also indicated differences by gender. Female foster youth were $70 \%$ more likely to report depression tendency $(\mathrm{AOR}=1.70 ; \mathrm{CI}=1.30-2.23)$ and $96 \%$ more likely to report suicidal ideation $(\mathrm{AOR}=1.96 ; \mathrm{CI}=$ 1.45-2.64). Also depicted in Table 2, by controlling for student demographics, results showed school connection was also associated with a decreased likelihood of depression tendency (AOR $=0.94 ; \mathrm{CI}=0.91-0.97)$ and suicidal ideation $(\mathrm{AOR}=0.93 ; \mathrm{CI}=0.90-0.96) . \mathrm{In}$ addition, caring relationships was significantly related to lower odds of suicidal ideation $(\mathrm{AOR}=0.85 ; \mathrm{CI}=0.77$ 0.93). High expectations were associated with a higher likelihood of suicidal ideation (AOR = $1.13 ; \mathrm{CI}=1.03-1.24)$.

\section{Discussion and implications}

Past research has found that foster youth experienced an array of challenges (i.e., family neglect, constant changes in foster care placements, and multiple school transitions) as they navigate the foster care and schooling systems (Harris et al., 2010; Pilowsky \& Wu, 2006). These life events place foster youth at an increased risk of mental health problems, including depression tendency and suicidal ideation (Keller, Salazar, \& Courtney, 2010; Stoner et al., 2015). A caring school climate where students feel connected to their school community and are supported by teachers and other school adults, plays a protective role in the social and emotional well-being of youth experiencing adversity (e.g., LGBTQ youth, military-connected youth) (De Pedro et al., 2015; Elliot et al., 2010; Marachi et al., 2006; Thapa et al., 2013). In alignment with past research on school climate, this study posited that a positive school climate is associated with lower rates of depression tendency and suicidal ideation among foster youth. 
In this study, we also acknowledge the diversity of foster youth. As such, we explored race and gender as factors that may influence rates of depression tendency and suicidal ideation within the foster youth population.

\subsection{Protective role of school climate}

The results of this study indicated that a positive school climate-school connection and caring relationships - is associated with lower rates of suicidal ideation among foster youth. These results are in alignment with past school climate research. A large number of studies conducted on youth facing adversity has found that students who feel a strong sense of belonging in school, and who have trusting relationships with teachers and other school staff demonstrate enhanced well-being and a lower likelihood of depression tendency and suicidal ideation (Cohen et al., 2009; Thapa et al., 2013). In addition, research on foster youth found that some foster youth view schools as sanctuaries - places where they can find social and emotional support and belonging when they face challenging life events (e.g., constant change while within the foster care system, abuse, and neglect) (Hass \& Graydon, 2009). School connection and caring relationships with school adults may also play a role in promoting prosocial behavior among youth facing adversity (Thapa et al., 2013). Future studies could explore the development and implementation of programs and practices aimed at supporting the well-being of foster youth and their impact on the well-being and pro-social behaviors of youth in foster care. One unexpected finding was the positive association between high expectations and suicidal ideation. 


\subsection{Gender differences in mental health among foster youth}

The results of this study indicated that female foster youth had higher rates of depression tendency and suicidal ideation when compared to male foster youth. While no previous studies have examined gender differences in the foster youth population, scholars have written extensively about the varied mental health outcomes among boys and girls in the general youth population. Researchers have found marked differences in mental health outcomes as they relate to gender, beginning in early adolescence. As an example, Rosenfeld \& Mouzon (2013) concluded that adolescent girls suffer more than boys from internalizing disorders, which often transform into feelings of depression, anxiety, and suicidal ideation. They also noted that adolescent girls struggle with a greater sense of loss, hopelessness, and feelings of helplessness when it comes to attempting to improve their conditions. Future research is necessary for exploring other targeted differences in mental health outcomes among foster youth, including marginalized subgroups within the female foster youth population (i.e., lesbian, gay, bisexual, transgender youth, immigrant students, youth living in poverty).

The current study also revealed about 50.5\% of female foster youth reported depression tendency, compared to $32.7 \%$ of male foster youth, while $36.3 \%$ of female foster youth reported suicidal thought, compared to $21.0 \%$ of male foster youth. This rate of suicidal ideation is startling and is higher than other vulnerable groups analyzed in the CHKS (e.g., LGBTQ youth), warranting the attention and support of school mental health professionals and other school staff. More research is necessary to examine risk and protective factors influencing mental health among female foster youth. Knowledge about risk and protective factors can be used to design and tailor suicide prevention programs and supports for female foster youth. 


\subsection{Racial differences in mental health among foster youth}

This study examined racial differences in the rates of depression tendency and suicidal ideation among foster youth. The bivariate analyses indicated that Black, Asian/PI, multiracial, American Indian, and Latino foster youth reported lower rates of depression tendency and suicidal ideation than White foster youth. Findings from our research add to past research comparing mental health outcomes of Black foster youth (Harris et al., 2010; Sullivan et al., 2010). Sullivan et al. (2010) discovered that White foster youth were nearly three times as likely to have a lifetime diagnosis of depression compared to Black foster youth. Further, Black foster youth had significantly lower odds of lifetime mood, anxiety, and substance use disorders than White foster youth (Harris et al., 2010). Some studies have shown that other sources of cultural capital and familial and community support can help youth of color navigate challenging life events and systems (i.e., schools, foster care) (Carter, 2003; Yosso, 2005).

While past studies have focused on comparisons between Black and White foster youth, this study explored depression tendency and suicidal ideation among other racial minority groups. Results from the multivariable logistic regression analyses indicated that when compared to White foster youth, Latino foster youth were less likely to report depression tendency and suicidal ideation, after controlling for other demographic factors. Given that Latinos are the largest racial minority group in the American youth population, more research exploring mental health outcomes among Latino foster youth is warranted. Also, findings found that Black youth had lower rates of depression tendency and suicidal ideation, when compared to White peers. Other studies have found that Black youth have culturally-based assets that may contribute to their well-being. In one study on low income Black youth, Carter (2003) examined the coexistence of dominant and non-dominant cultural capital among low-income Black youth. 
According to Carter (2003), the dominant cultural capital was critical to the social, academic, and economic attainment for youth. Also, the non-dominant cultural capital was instrumental in the status positioning within socially marginalized groups. Therefore, this may imply that foster youth of color who are placed in custody with those of another race, possess cultural capital that may contribute as a form of support. Yosso (2005) constructed a model of community and cultural wealth, articulating how youth of color persist through experiences of racism and institutional barriers to achieve academic success and emotional well-being. We recommend that future research and theoretical frameworks explore protective factors influencing the emotional well-being of foster youth of color.

\subsection{Limitations and future directions}

This study does have limitations. First, the data are cross-sectional, and thus causality cannot be explored. Second, as with much research on school climate, this study assesses school climate through self-reported survey items. The CHKS is comprised of only student self-reported items. Objective measures of school climate such as presence of police officers, video surveillance systems, average years of teachers' experience, and student-teacher ratio may have been beneficial to the measurement of school climate in this study. However, the CHKS does not include these items. Third, the study sample was majority non-White, and the setting was California schools, a unique cultural context. Fourth, foster youth experience more school transitions than the general youth population, impacting their access CHKS. To that point, this study may have underreported the number of foster youth where the CHKS was administered. This may have introduced error in the study's results. Also, the CHKS does not include an item assessing number of school transitions. Future studies should look to account for the number of school transitions when examining the mental health and school climate perceptions of foster 
youth. Past research has found a negative association between school transitions and school climate. Fifth, two items were utilized to assess emotional distress. While suicidal ideation and feelings of sadness and hopelessness are indicators of emotional distress symptoms, it is recommended that future studies utilize standardized scales to more reliably capture emotional distress symptoms among foster youth. Sixth, the 2013-2014 and the 2014-2015 administrations of the CHKS did not include a variable assessing socioeconomic status. Studies have found that poverty is directly correlated with mental health and school climate. We recommend that future studies examining mental health and school climate, if possible, account for poverty. Seventh, this study did not incorporate a comparison group (i.e., youth living with parents and not in foster care). We recommend future studies utilize a comparison group to compare gender and racial differences in mental health in both populations and assess the potential differential impact of school climate on the mental health of youth in foster care and those living with parents. Last, we recognize that because some districts required informed consent, the CHKS may have an underrepresentation of youth in foster care; some foster youth may not have had access to guardians to provide consent for their participation in the study.

\section{Conclusion}

Youth in foster care often face challenges in the foster system and schools, including multiple home placements, school transitions, and emotional neglect from parents and guardians. These life stressors place foster youth at an increased risk of depression tendency and suicidal ideation. A caring and affirming school climate, specifically a sense of connectedness to a school and teacher and school adult support, could play a protective role in the mental health and wellbeing of foster youth. However, few studies have examined school connectedness and adult 
support on the mental health outcomes of foster youth. Additionally, few studies have explored differences in school climate and emotional distress by race and gender. This study found alarming rates of suicidal ideation and feelings of sadness and hopelessness among female foster youth. Results also pointed to racial minority foster youth showing a significantly lower rate of suicidal ideation and depression tendency when compared to White peers. Also, higher levels of school connectedness and school adult support were associated with lower odds of suicidal ideation and chronic sadness among foster youth.

The findings in this study could inform current programs aimed at enhancing the climate of schools. First, as evidence from this study suggests, when implementing programs and strategies that promote connectedness and teacher-student relationships, it is critical that these programs consider the needs of foster youth, especially girls in the foster care system. Practitioners could be trained to become more aware of the unique needs of foster youth, specifically issues pertaining to school mobility and challenges within the foster care system. Second, current programs for youth in foster care tend to focus on mental health referrals. The findings of this study suggest, in addition to school counseling, mental health professionals and school leadership work together to devise strategies to enhance school connectedness and caring adult relationships for foster youth. Third, this study drew from the CHKS, which, in addition to researchers, is available to school professionals. As such, we encourage school practitioners and leaders to use these readily accessible data to track the school climate perceptions and rates of depression tendency and suicidal ideation among foster youth attending their schools; doing so could better inform the allocation of resources for foster youth. 


\section{References}

Anderson, E. M., Blitz, L. V., \& Saastamoinen, M. (2015). Exploring a school-university model for professional development with classroom staff: Teaching trauma-informed approaches. School Community Journal, 25(2), 113-134.

Astor, R. A., Benbenishty, R., \& Estrada, J. N. (2009). School violence and theoretically atypical schools: The principal's centrality in orchestrating safe schools. American Educational Research Journal, 46(2), 423-461.

Austin, G., Bates, S., \& Duerr, M. (2014). Guidebook for the California Healthy Kids Survey part I: Administration. San Francisco, CA: West Ed. Retrieved from http://chks.wested.org/resources/chks_guidebook_1_admin.pdf

Brand, S., Felner, R., Shim, M., Seitsinger, A., \& Dumas, T. (2003). Middle school improvement and reform: Development and validation of a school-level assessment of climate, cultural pluralism, and school safety. Journal of Educational Psychology, 95(3), 570-588.

Carter, P. L. (2003). "Black" cultural capital, status positioning, and schooling conflicts for lowincome African American youth. Social problems, 50(1), 136-155.

Cederbaum, J. A., Gilreath, T. D., Benbenishty, R., Astor, R. A., Pineda, D., De Pedro, K. T., ... \& Atuel, H. (2014). Well-being and suicidal ideation of secondary school students from military families. Journal of Adolescent Health, 54(6), 672-677.

Cohen, J., McCabe, E., Michelli, N., \& Pickeral, T. (2009). School climate: Research, policy, practice, and teacher education. Teachers College Record, 111(1), 180-213.

Cornell, D., \& Huang, F. (2016). Authoritative school climate and high school student risk behavior: A cross-sectional multi-level analysis of student self-reports. Journal of Youth and Adolescence, 45(11), 2246-2259. https://doi.org/10.1007/s10964-016-0424-3 
Cyranowski, J. M., Frank, E., Young, E., \& Shear, M. K. (2000). Adolescent onset of the gender difference in lifetime rates of major depression: A theoretical model. Archives in General Psychiatry, 57(1), 21-27.

Daining, C., \& DePanfilis, D. (2007). Resilience of youth in transition from out-of-home care to adulthood. Children and Youth Services Review, 29(2007), 1158-1178.

De Pedro, K. T., Astor, R. A., Gilreath, T. D., Benbenishty, R., \& Berkowitz, R. (2015). School climate, deployment, and mental health among students in military-connected schools. Youth \& Society, 1-23. https://doi.org/10.1177/0044

De Pedro, K. T., Esqueda, M. C., \& Gilreath, T. D. (2017). School protective factors and substance use among lesbian, gay, and bisexual adolescents in California public schools. LGBT health, 4(3), 210-216.

De Pedro, K. T., Gilreath, T. D., \& Berkowitz, R. (2016). A latent class analysis of school climate among middle and high school students in California public schools. Children and Youth Services Review, 63(2016), 10-15.

Dworsky, A., White, C. R., O’Brien, K., Pecora, P., Courtney, M. E., Kessler, R., ... Hwang, I. (2010). Racial and ethnic differences in the outcomes of former foster youth. Children and Youth Services Review, 32(2010), 902-912.

Elliot, M., Cornell, D., Gregory, A., \& Fan, X. (2010). Supportive school climate and student willingness to seek help for bullying and threats of violence. Journal of School Psychology, 48(2010), 533-553.

Harris, M., Jackson, L., O’Brien, K., \& Pecora, P. (2010). Ethnic group comparisons in mental health outcomes of adult alumni of foster care. Children and Youth Services Review, 32(2010), 171-177. 
Hass, M., \& Graydon, K. (2009). Sources of resiliency among successful foster youth. Children and Youth Services Review, 31(2009), 457-463.

Huang, F. L., Eklund, K., \& Cornell, D. G. (2016). Authoritative school climate, the number of parents at home, and academic achievement. School Psychology Quarterly, 32(4), 480. https://doi.org/10.1037/spq0000182

Marachi, R., Astor, R. A., \& Benbenishty, R. (2006). Effects of student participation and teacher support on victimization in Israeli schools: An examination of gender, culture, and school type. Journal of Youth and Adolescence, 36(2), 225-240.

Moore, H., Benbenishty, R., Astor, R. A., \& Rice, E. (2017). The positive role of school climate on school victimization, depression, and suicidal ideation among school-attending homeless youth. Journal of School Violence, 1-13.

Nolen-Hoeksema, S., \& Girgus, J. S. (1994). The emergence of gender differences in depression during adolescence. Psychological Bulletin, 115(3), 424-443.

O’Malley, M., Voight, A., Renshaw, T. L., \& Eklund, K. (2015). School climate, family structure, and academic achievement: A study of moderation effects. School Psychology Quarterly, 30(1), 142-157. https://doi.org/10.1037/spq0000076

Pilowsky, D. J., \& Wu, L. T. (2006). Psychiatric symptoms and substance use disorders in a nationally representative sample of American adolescents involved with foster care. Journal of Adolescent Health, 38(4), 351-358.

Rosenfeld, S., \& Mouzon, D. (2013). Gender and mental health. In Handbook of the Sociology of Mental Health (pp. 277-296). New York, NY: Springer. 
Stoner, A. M., Leon, S. C., \& Fuller, A. K. (2015). Patterns of reduction in symptoms of depression for children and adolescents in foster care. Journal of Child and Family Studies, 24(3), 784-797.

Sullivan, M. J., Jones, L., \& Mathieson, S. (2010). School change, academic progress, and behavior problems in a sample of foster youth. Children and Youth Services Review, 32(2), 164-170.

Thapa, A., Cohen, J., Guffey, S., \& Higgins-D’Allesandro, A. (2013). A review of school climate research. Review of Educational Research, 83(3), 357-385.

Wilson, D. (2004). The interface of school climate and school connectedness and relationships with aggression and victimization. The Journal of School Health, 74(7), 293-299.

Yosso, T. J. (2005). Whose culture has capital? A critical race theory discussion of community cultural wealth. Race, Ethnicity, and Education, 8(1), 69-91.

Zetlin, A., MacLeod, E., \& Kimm, C. (2010). Beginning teacher challenges: Instructing students who are in foster care. Remedial and Special Education, 33(1), 4-13. 
Table 1

Demographic Characteristics of Study Sample

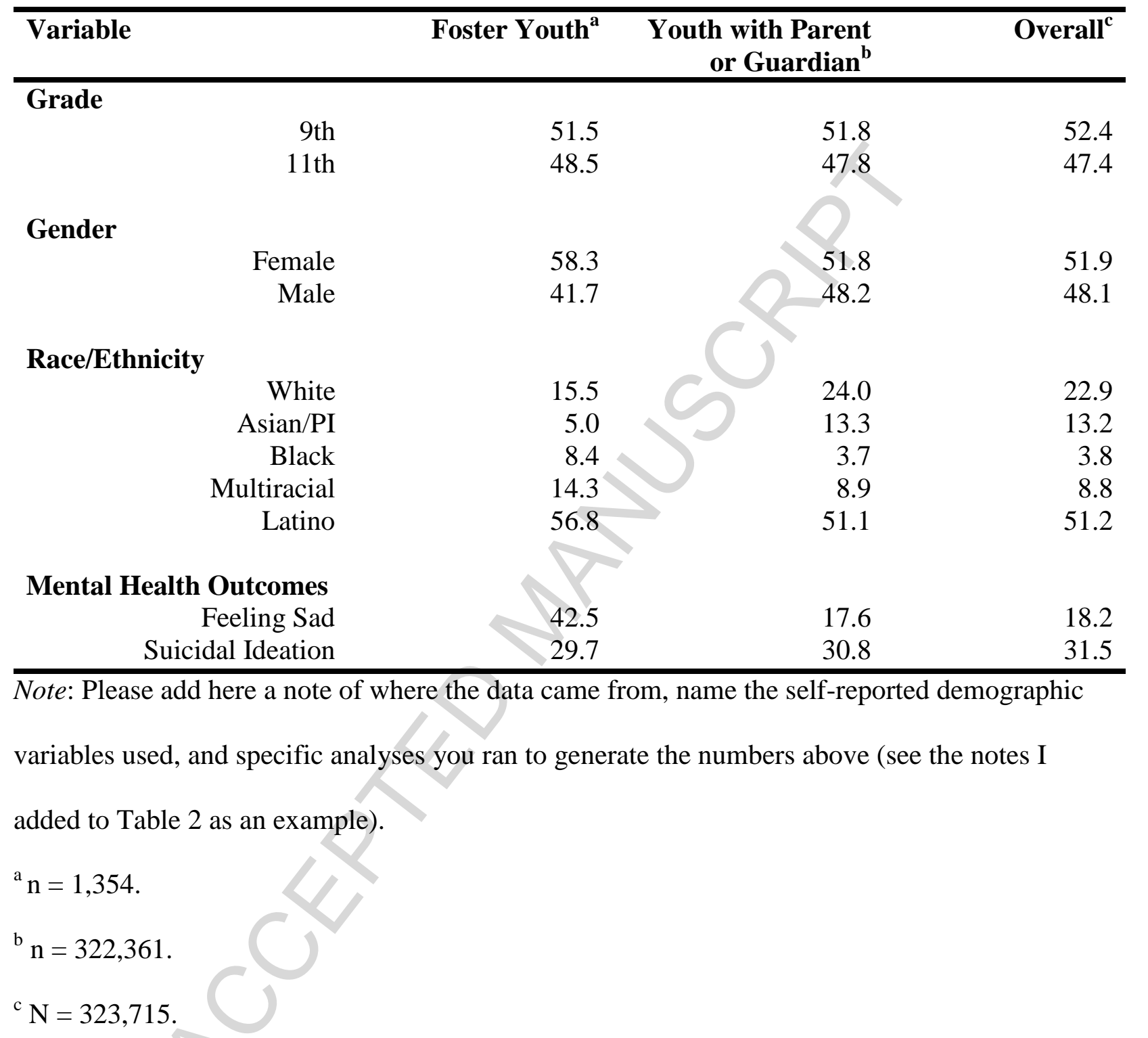


Table 2

Associations Among Demographics, School Climate, Suicidal Ideation, and Feeling Sad Among

Foster Youth in California Public Schools in Years 2013-2014 and 2014-2015

\begin{tabular}{|c|c|c|}
\hline Variable & $\begin{array}{r}\text { Depression } \\
\text { Tendency }\end{array}$ & $\begin{array}{l}\text { Suicidal } \\
\text { Ideation }\end{array}$ \\
\hline \multicolumn{3}{|l|}{ Race/Ethnicity } \\
\hline White (ref) & 1.00 & 1.00 \\
\hline & $.85(.45-1.60)$ & $.31 *(.12-.78)$ \\
\hline Asian & & $.38 *(.17-.82)$ \\
\hline Black & $.64(.38-1.07)$ & $.36^{*}(.20-.65)$ \\
\hline Multiracial & $.63 *(.41-.98)$ & $.63(.39-1.04)$ \\
\hline Latino & $.67 *(.48-95)$ & $.54 *(.37-.79)$ \\
\hline \multicolumn{3}{|l|}{$\begin{array}{l}\text { Biological Sex } \\
\text { (ref) }\end{array}$} \\
\hline & & $1.96 *(1.45-2.64)$ \\
\hline Female & & $.98(.88-1.11)$ \\
\hline & $-.97)$ & $.93 *(.90-.96)$ \\
\hline School Protective & & $.85^{*}(.77-.93)$ \\
\hline Factors & & $1.13 *(1.03-1.24)$ \\
\hline School connection & & $1.04(.98-1.10)$ \\
\hline
\end{tabular}

Notes. Using logistic regressions, we examined the associations among demographics, school

climate, suicidal ideation, and feelings of sadness among foster youth in California public

schools.

$\mathrm{n}=1823$.

$* \mathrm{p}<.05$ 


\section{Highlights}

- A positive school climate is associated with lower rates of depression tendency and suicidal ideation among foster youth

- Female foster youth reported higher rates of depression tendency and suicidal ideation when compared to their male counterparts.

- Foster youth of color were significantly less likely to report depression tendency and suicidal ideation than their White peers 